\title{
Sun Compass-based Spatial Learning Impaired in Homing Pigeons with Hippocampal Lesions
}

\author{
Verner P. Bingman and Tammy-Jo Jones \\ Department of Psychology, Bowling Green State University, Bowling Green, Ohio 43403-0228
}

\begin{abstract}
The hippocampal formation is known to be critical for spatial cognition, for example, regulating the learning of environmental maps. But how is a spatial map learned, and what is the role of the hippocampal formation in the learning process? The sun compass is perhaps the most ubiquitous, naturally occurring spatial orientation mechanism found in the animal kingdom. The sun compass may also serve as a directional reference that supports spatial learning. We report that homing pigeons with hippocampal lesions were unable to use the sun compass to learn the directional location of food in an outdoor, experimental arena. Homing pigeons with lesions of the caudal neostriatum readily learned the same task, and showed appropriately shifted directional responses following a clock-shift manipulation demonstrating that they were indeed using the sun compass to learn the task. Finally, both hippocampal and control lesioned birds quickly learned a procedurally similar task where a color cue identified the location of food in the same experimental arena. The results indicate that hippocampal lesions impair sun compass use in the context of learning. As such, the results support the hypothesis that the importance of the hippocampal formation in spatial cognition may be related to its participation in a neural process in which information from a directional reference, in this case the sun compass, is used to learn the directional relationship among stimuli in space.

IKey words: hippocampus, spatial cognition, sun compass, homing pigeon, cognitive map, navigation]
\end{abstract}

The vertebrate hippocampal formation (abbreviated below as HF) is critical for spatial cognition (O'Keefe and Nadel, 1978; Nadel, 1991; Bingman, 1992; Jarrard, 1993). Lesioning HF impairs spatial cognition in a wide variety of experimental contexts including eight-arm radial maze (Olton et al., 1979), and water maze (Morris et al., 1982) in rats, homing in pigeons (Bingman, 1992), and seed recovery in caching birds (Krushinskaya, 1966; Sherry and Vaccarino, 1989). Neurons in the rat HF, so-called place cells (O'Keefe and Conway, 1978), respond when an animal is in a particular environmental location. Other neurons, so-called direction-sensitive cells of the postsubiculum, respond when an animal is oriented in a particular direction with respect to some external reference (Taube et al., 1990). Finally, features of HF anatomy have been found to correlate with spatial cognitive ability (Lipp et al., 1987) or natural spatial behavior

\footnotetext{
Received Oct. 21, 1993; revised Feb. 28, 1994; accepted May 5, 1994.

This work was supported by a grant from the National Science Foundation and a Bowling Green State University Alumni Undergraduate Research Award. We thank Colleen Cousino, Meliha Duncan, Lauren Riters, and Andy Wickiser for their help in various phases of this study.

Correspondence should be addressed to Verner P. Bingman at the above address. Copyright (C) 1994 Society for Neuroscience $0270-6474 / 94 / 146687-08 \$ 05.00 / 0$
}

(birds: Krebs et al., 1989; Sherry et al., 1989; mice: Jacobs et al., 1990).

As compelling as the connection between $\mathrm{HF}$ and space is, it nonetheless remains unclear what particular role HF plays in spatial cognition. What cognitive mechanism(s) is regulated by HF that can explain why birds and mammals without an HF have difficulty learning to navigate or identify goal locations? Of the various models developed to explain HF function, at least two have specifically attempted to explain the relationship between HF and space. O'Keefe and Nadel (1978) have argued that HF participates in the learning and operation of cognitive maps. Sutherland and Rudy (1989; but see Davidson et al., 1993) have argued that HF participates in configural learning with space as one configural component. But what is it about learning a cognitive map that HF may be particularly well suited to regulate? What is it about learning a spatial configuration that may necessarily involve HF?

To examine this issue, an animal model system should be selected in which both spatial behavior mechanisms and mechanisms that control spatial learning have been well described. Pigeon homing behavior, a cornerstone of ethological research for more than 40 years, appears particularly well suited. The complex array of spatial mechanisms homing pigeons can employ to return to their loft (Wallraff, 1990; Berthold, 1991) and how such mechanisms are learned (Wallraff, 1974; Wiltschko and Wiltschko, 1982, 1987; Ioalé et al., 1990) have been reasonably well described. A further advantage is that homing pigeons can be studied under natural environmental conditions that allow them to display the richness of their navigational ability (Bingman, 1992).

IIF lesions have been found to disrupt the learning of two spatial navigation mechanisms in homing pigeons. First, homing pigeons with $\mathrm{HF}$ lesions are impaired in learning to navigate home from distant, unfamiliar locations (Bingman et al., 1990; Bingman and Yates, 1992). To navigate home from a distant, unfamiliar location, homing pigeons rely on their so-called "navigational map" (Kramer, 1959; Wallraff, 1974). Although it is unclear if the navigational map is a map in the literal sense of representing at the neural level the topographical relationship of stimuli in space, it does allow birds to determine the direction home following displacement. Second, homing pigeons can also rely on familiar landmarks as an independent navigational strategy to return home when in sensory contact with them (Wallraff et al., 1993). HF lesions also disrupt learning to navigate by familiar landmarks in contexts requiring novel responses to those landmarks (Bingman et al., 1989; Bingman and Mench, 1990; Bingman, unpublished observations).

In homing pigeons, the learning of two independent spatial navigation mechanisms is disrupted by HF lesion. As such, an indication of the supporting cognitive mechanism(s) that is dis- 
rupted by HF lesion could perhaps be gained by determining common processes associated with learning each of these navigational mechanisms. What aspects of learning a navigational map are potentially shared by learning to navigate by familiar landmarks? Wallraff (1974) suggested that in learning a navigational map, a pigeon determines how some stimulus quality varies along a directional axis or gradient. It is known that homing pigeons can learn the directional origin of odors carried by the wind and use that information to learn a navigational map (Ioalé et al., 1990). Wiltschko and Wiltschko (1982, 1987) have argued that a pigeon learning to use familiar landmarks does so by determining the directional relationships between the loft and other stimuli in space (c.g., conspicuous buildings) as well as perhaps the directional relationships among the other stimuli. Although in some cases speculative, these observations and ideas share one critical feature: in learning a navigational map or learning to navigate by familiar landmarks, the location of stimuli in space is thought to be represented in the CNS within the framework of some directional reference. Using a human analogy, in building a map one first defines north, south, east, and west and then places stimuli on the map with respect to the directional reference set up initially.

The hypothesis. The data from homing pigeons suggest that $\mathrm{HF}$ is involved in a cognitive process that allows an animal to learn the location of stimuli in space through the use of some directional reference. But what is meant by a directional reference? Generally, such a reference should allow an animal to set up a directional framework or polarize space in some way. In birds under natural conditions, as is the case for most animals (Able, 1991), the primary directional reference is the sun compass (Schmidt-Koenig, 1979; Wiltschko and Balda, 1989). The sun compass is a time-compensated mechanism that defines directions in space. By using its internal clock, a bird is able to take into account the movement of the sun during the course of the day, thus maintaining a stable directional framework (Schmidt-Koenig, 1979). It is essential for navigation, allowing a pigeon to orient home whether identifying the homeward direction with use of its navigational map (Schmidt-Koenig, 1958) or perhaps familiar landmarks (Graue, 1963; Füller et al., 1983). More importantly, the sun compass is a likely candidate for the directional reference used to learn a navigational map or landmark navigation (Wallraff, 1974; Wiltschko and Wiltschko, 1987). As such, the hypothesis predicts that HF-lesioned birds are impaired at learning to navigate specifically because they cannot use the sun compass as a directional reference to learn the directional relationship among stimuli in space.

We report the results of two experiments indicating that HFlesioned homing pigeons are impaired in a task that requires them to use the sun compass to locate the directional position of food in an experimental arena, but are unimpaired when color can be used to locate food in the same arena. The data suggest that $\mathrm{HF}$ participates in a cognitive process in which a directional reference (in this case the sun compass) is used to learn the location of stimuli in space, thus offering an explanation for why HF lesions impair spatial learning.

\section{Materials and Methods}

\section{Subjects and surgical procedures}

Sixteen homing pigeons (Columba livia) were used in this study. All the birds were tested at least six months after surgery. During the time between surgery and testing, the birds were used in homing experiments and had all successfully homed from at least $20 \mathrm{~km}$ away. Eight birds were subjected to hippocampal lesions (four at 4 weeks of age before ever leaving the loft and four as adults with previous homing experience). Eight birds were subjected to control lesions of the caudal neostriatum (again four young birds and four experienced adults). The caudal neostriatum (abbreviated below as $\mathrm{CN}$ ) was chosen for control lesions because this brain region is thought to play a primary role in auditory processing (Brauth et al., 1987) and therefore contribute little to the task under study.

Initially, the study was to include an unlesioned control group. Early in the experiment, two unlesioned control birds were tested, and they learned the task in a manner indistinguishable from $\mathrm{CN}$-lesioned birds (they took seven and nine sessions to reach criterion; see below). Additionally, $\mathrm{CN}$-lesioned birds have been used as controls in a number of recent experiments examining navigational learning and homing performance (Bingman, unpublished observations). No differences have been found in homing performance between untreated and $\mathrm{CN}$-lesioned pigeons indicating no difference in navigational learning that might involve the sun compass. It was decided, therefore, that $\mathrm{CN}$-lesioned birds were sufficient as controls and unlesioned control pigeons were eliminated from the study.

For surgery, pigeons were anesthetized with a combination of xylazine $(20 \mathrm{mg} / \mathrm{ml}, 0.5 \mathrm{ml} / \mathrm{kg}$ body weight, i.m.) followed by ketamine $(100 \mathrm{mg} /$ $\mathrm{ml}, 0.5 \mathrm{ml} / \mathrm{kg}$ body weight, i.m.) and placed in a stereotaxic apparatus. The ketamine doses were repeated as necessary to maintain a surgical depth of anesthesia. The intended incision site was infiltrated with $\mathrm{xy}-$ locaine and, following incision and retraction of the scalp, a Moto-Flex tool was used to penetrate the skull. A small bone flap was removed in order to allow the electrodes access to the brain. The electrodes used were stainless steel insect pins that had been insulated with epoxy paint. Exposed tips were $5.0 \mathrm{~mm}$ in length for the $\mathrm{HF}$ lesions and $3.0 \mathrm{~mm}$ for the $\mathrm{CN}$ lesions.

For the HF lesions, the electrode was positioned in the brain according to the stereotaxic coordinates obtained from the atlas of Karten and Hodos (1967). The intended target regions were the hippocampus and parahippocampus. Bilateral, anodal electrolytic lesions were made in the target region. For each side of the brain, three lesions were made with the electrode oriented parallel to the anterior-posterior axis of the brain. The lesion parameters can be found in Bingman and Hodos (1992).

The same basic procedure was used for the $\mathrm{CN}$ lesions. The intended target region was the caudal neostriatum. For each side of the brain two lesions were made with the electrode oriented parallel to the dorsalventral axis of the brain. The parameters (from the atlas of Karten and Hodos, 1967) for the first lesion were anterior coordinate 5.2, lateral coordinate 3.5 , vertical coordinate 9.5 for $15 \mathrm{sec}$ at $3 \mathrm{~mA}$. The parameters for the second lesion were anterior coordinate 5.2, lateral coordinate 5.0, vertical coordinate 9.5 for $15 \mathrm{sec}$ at $3 \mathrm{~mA}$. The lesion parameters were chosen to produce damage volume similar to the $\mathrm{HF}$ lesions.

For all testing, the birds were kept at approximately $85 \%$ of their freefeeding weights.

\section{Behavioral testing and data analysis}

Sun compass and the directional location of food. Previous studies have employed outdoor experimental arenas to investigate the sun compass of pigeons (Kramer and Riese, 1952; Schmidt-Koenig, 1958, 1961). An experimental arena similar to that used in previous studies was employed to examine the effect of HF lesion on the ability of pigeons to locate food directionally using the sun compass. The octagonal test arena ( $1 \mathrm{~m}$ in diameter) had a clear, Plexiglas top. Extending from the arena floor to a hole at the center of the Plexiglas top was an opaque, cylindrical start chamber (covered at the top but bottomless, $30 \mathrm{~cm}$ in diameter, $13.5 \mathrm{~cm}$ in height). The start chamber could be lifted from the floor of the arena through the hole in the Plexiglas top by a cord attached to a pulley system. At the center of the eight wooden, opaque walls (wall height $13.5 \mathrm{~cm}$ ) was a square opening, outside of which a food cup was hung. Blinders were attached to the food cups, preventing the birds from sccing any environmental cues through the holes in the arena walls. From the arena, which was located outdoors in an open field, the birds could see only the sky, sun, and experimental observer.

Birds were tested once a day on sunny days between April and October. Testing took place either in the morning [defined as the sun being between geomagnetic $100^{\circ}$ and $160^{\circ}\left(\right.$ north $\left.=0^{\circ}\right)$ ] or afternoon (defined as the sun being between geomagnetic $200^{\circ}$ and $260^{\circ}$ ). It was originally 
intended to switch randomly between morning and afternoon testing sessions. This proved unrealistic because of weather changes and the unpredictable availability of the sun. As such, the birds were tested once a day taking advantage of the times the sun was visible. Generally, this resulted in the pigeons switching irregularly between morning and afternoon sessions. However, they were never tested more than $3 \mathrm{~d}$ in a row in the morning or afternoon.

The time of testing also varied within morning and afternoon sessions. This was done to encourage the birds to rely on their time compensated sun compass rather than learn a fixed angle response to the sun (i.e., food is always located $90^{\circ}$ clockwise of the sun regardless of the time of day), which pigeons have been reported to do (Kramer and Riese, 1952; Schmidt-Koening, 1958, 1961). For each test animal, food was always located in the food cup located in the same compass direction. For four birds in each group the direction was north, three birds in each group south, and one in each group east.

Testing would begin after the birds were shaped to take food from the food cups. It is important to note that there were no detectable differences between the HF and $\mathrm{CN}$ birds in their tendency to explore the arena or learning to stick their heads through the wall holes to gather food. The first trial of an experimental session would begin with a bird first being transported to the arena at the test site and placed in the start chamber. The experimenter could not see the bird when it was in the start chamber. After about $10 \mathrm{sec}$, the start chamber would be lifted through the hole in the Plexiglas top via the attached pulley system and the bird released. A bird was then allowed to explore the cups by sticking its head through the wall openings. A choice was scored if a bird's beak passed the vertical plane of the outside wall, which was the only way a bird could detect the presence of food. The experimental observer, blind to experimental condition, scored the birds' choices.

If a bird's first choice was the cup with food or either of the two immediately adjacent cups, which were empty, the trial was scored as correct. A directional response (e.g., north) would have brought a bird to the same food cup on each trial only if the starting point was the same. The start chamber was designed to ensure that the birds made their directional choices from about the same location from trial to trial. Sometimes, however, a bird would drift from center before initiating its choice response. As such, the adjacent food cups were considered correct responses to take into account the variability in starting position from trial to trial. Errors were scored if a bird chose any of the other cups. Errors were counted until a bird chose one of the three correct cups. The trial ended when a bird found and consumed the food.

Before beginning the next trial, a bird was returned to the start chamber (they returned by themselves to the center of the arena where the start chamber was dropped over them with the pulley mechanism), the cage rotated, the cups alternated, the observer's position moved, and seed placed again in the cup in the correct compass direction. Intertrial intervals were approximately $30 \mathrm{sec}$, but varied depending primarily on how quickly the bird was returned to the start chamber. An experimental session consisted of 20 trials. Each bird was tested until it met a criterion of three sessions in a row of $80 \%$ correct trials or better $(38 \%$ would be chance), with the three sessions not taking place all in the morning or all in the afternoon. Birds were tested for a maximum of 20 sessions. A between-group difference in sessions to criterion was tested with a $t$ test. Additionally, ANOVAs were carried out to test for possible improvement in the HF-lesioned birds by comparing (1) the mean number of incorrect trials (first choice errors) per session, (2) the total number of errors committed, and (3) the mean length of the food directed vector (h, a measure of how well the directional choices clustered around the food direction; Batschelet, 1981) per session across four blocks of five sessions (sessions 1-5, 6-10, 11-15, 16-20; none of the HF-lesioned birds learned the task). A similar set of ANOVAs were performed on the control lesioned birds across four blocks of two sessions (six of eight control birds were tested for at least eight sessions).

Behavior after clock shift. All control birds successfully learned the food location task. To determine if they were indeed using the sun compass to locate the food, the birds were first given an additional overtraining session. The 20 directional choices chosen by each bird at the beginning of each trial during the overtraining session were then subjected to circular statistics (Batschelet, 1981) and a mean direction calculated for each individual. Subsequently, the birds were brought indoors and held in a room under an artificial light regime that had lights on $6 \mathrm{hr}$ after sunrise and lights off $6 \mathrm{hr}$ after sunset. After at least $6 \mathrm{~d}$ under the clockshift condition, the birds were retested once during their subjective morning or real afternoon. The testing procedure for the clock-shift session was identical to that employed during initial learning except no food was available and a trial ended with the first food cup choice. Food was eliminated because we did not want to bias the birds toward the true (initial learning) food direction or what the food direction would have been based on their clock-shifted sun compass. For the clock-shift session, the 20 directional choices made by each bird were subjected to circular statistics and a mean direction calculated for each individual. The overtraining session and clock-shift session mean directions were compared with the Watson $U^{2}$ test (Batschelet, 1981).

Color discrimination. At least 4 months after completing the sun compass-food location task, four HF-lesioned and four control lesioned birds were tested for their ability to locate a food reward in the same experimental arena changed such that each of the eight walls was uniquely coded with colored paper. Generally, the same procedures were employed. However, all testing now took place indoors, birds obtained food by choosing the food cup behind the wall of a specific color (for all birds the correct response was red), and errors for each trial were counted until a bird chose the correct color. Before each trial, the experimental arena was rotated, the position of the observer was moved and the food cups were alternated to ensure that only color reliably predicted the location of the food reward. Birds were tested until scoring $80 \%$ correct trials or better for three sessions in a row. A between group difference in sessions to criterion was tested with a $t$ test. Error reduction across sessions and a between group difference in errors across sessions were analyzed with an ANOVA.

\section{Histology and lesion reconstruction}

Following behavioral testing, the subjects were deeply anesthetized with sodium pentobarbital intravenously and were perfused via the left ventricle with normal saline followed by Heidenhain's solution (without mercuric chloride). The bird's head was severed from the body, the calvarium was removed, and the brain was fixed overnight in Heidenhain's solution. After fixation the brain was placed in the stereotaxic instrument and blocked $i n$ situ as described by Karten and Hodos (1967). It then was removed from the skull and placed in $10 \%$ formal saline for additional fixation and storage. Several days later the brain was washed in tap water, dehydrated via a progressive ethanol series, cleared in xyline, and embedded in paraffin. The brains were frontally cut at $10 \mu \mathrm{m}$. Every 10 th section through the telencephalon was mounted using a diluted albumin-glycerol solution and subsequently stained with a modified version of the Klüver-Barrera stain (Klüver and Barrera, 1953) for visualization of cell bodies and mylenated axons. Each brain was examined microscopically for evidence of necrosis, gliosis, cell loss, and retrograde degeneration.

The lesions were reconstructed, without knowledge of the behavioral data, on standard drawings of the pigeon brain derived from the Karten and Hodos atlas (1967).

\section{Results}

\section{Histology}

Summarized in Figure 1 are the lesion reconstructions from the $\mathrm{HF}$ - and CN-lesioned birds. The extent of HF damage was similar to that described in previous studies (e.g., Bingman et al., 1990). Both components of the dorsomedial forebrain region, the hippocampus and parahippocampus, were extensively damaged. Some damage to adjacent structures, including the hyperstriatum accessorium, dorsolateral cortex, and hyperstriatum ventrale, was found. $\mathrm{CN}$ lesions were successfully targeted in the caudal neostriatum. Some damage to the hyperstriatum ventrale laterally and dorsolateral cortex was also present.

\section{Sun compass and the directional location of food}

The data summarized in Figure 2 reveal that the CN-lesioned birds learned the task in about eight experimental sessions. In contrast, none of the HF-lesioned birds learned the location of the food within the limit of 20 sessions [between-group difference $t(14)=18.9, P<0.001$, assuming conservatively that the HF-lesioned birds would have learned the task in 23 sessions]. 

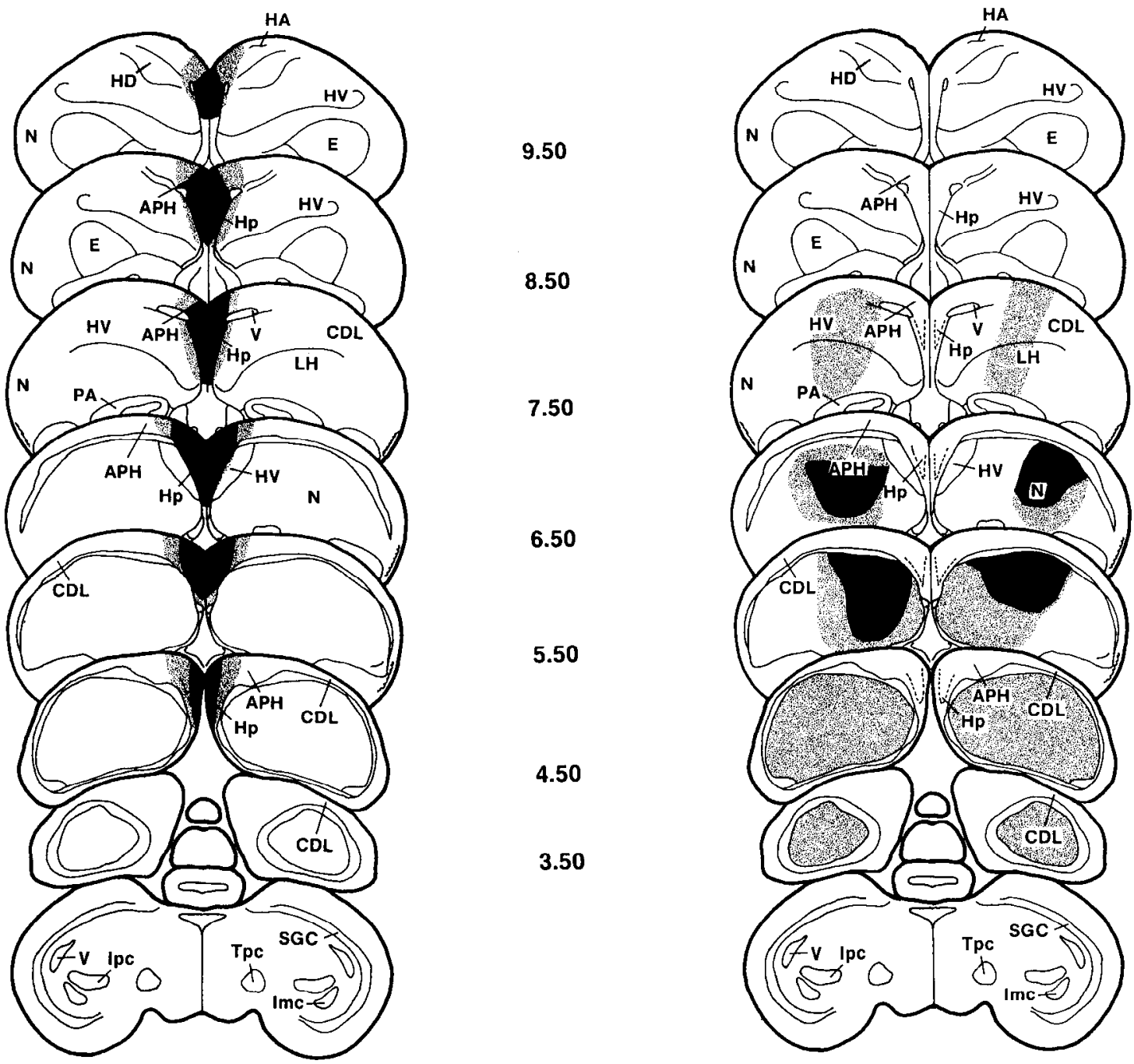

Figure 1. Lesion reconstructions of hippocampal- (HF, left $)$ and caudal neostriatum- (CN, right) ablated pigeons. Black areas represent lesioned portions common to at least six of cight $\mathrm{HF}$ and $\mathrm{CN}$ birds. Dotted areas represent lesioned portions common to at least two of the eight $\mathrm{HF}$ and $\mathrm{CN}$ birds. $A P H$, area parahippocampalis; $E$, ectostriatum; $H A$, hyperstriatum accessorium; $H D$, hyperstriatum dorsale; $H I S$, hyperstriatum intercalatus superior; $H p$, hippocampus; $I m c$, nucleus isthmi, pars magnocellularis; $I p c$, nucleus isthmi, pars parvocellularis; $L H$, lamina hyperstriatica; $N$, neostriatum; $P A$, paleostriatum augmentatum; $S G C$, stratum griseum centrale; $T p c$, nucleus tegmenti pedunculo pontinus, pars compacta; $V$, ventriculus. Drawings of transverse sections, stereotaxic coordinates, and nomenclature were derived from the atlas of Karten and Hodos (1967).

HF lesion has a devastating effect on the ability of pigeons to use the sun compass to locate a food reward.

Given the failure of the HF-lesioned birds to learn the task within the 20 test sessions, it is important to consider whether they displayed any improvement over the course of testing that would suggest some learning took place and that they might have eventually approached control performance with more training. Figure 3 summarizes the mean number of incorrect trials per session (errors on the first choice of each trial) recorded from the HF-lesioned birds over four blocks of five sessions. Mean number of incorrect trials decreased only marginally across session blocks $[F(3,21)=1.27 ; P>0.10]$, indicating virtually no improvement with training. Total number of errors per session block also did not change $[F(3,21)=0.281 ; P>0.10]$.

Figure 3 also summarizes the mean number of incorrect trials per session recorded from the CN birds $(N=6$; two birds, the best performers, had reached criterion before finishing eight sessions and were excluded from the statistical analysis) over four blocks of two sessions. Mean number of incorrect trials decreased significantly, particularly during session block $4[F(3$, 15) $=3.79 ; P=0.01]$.

The absence of improvement on the part of the HF birds reflected in error scores is striking. A further analysis of the behavior of the HF pigeons was performed to explore more fully their apparent inability to learn. The first directional responses of each bird at the beginning of each trial during a session $(N$ $=20$ ) were subjected to circular statistics (Batschelet, 1981). The critical measure calculated for each session was $h$, the length of the food directed vector (if this were a homing study $h$ would stand for the length of the homeward directed vector). $h$ can vary from 1.0 (all responses directed toward the food) to -1.0 (all responses directed $180^{\circ}$ opposite the food cup). It is a measure of how well the first directional choices on each trial clustered around the direction of food. For the HF-lesioned birds, mean length of the food directed vector (h) for each session increased only marginally across the four session blocks of five sessions each $[F(3,21)=2.09 ; P>0.10]$. During the first block of five sessions, mean $h$ was $0.21(\mathrm{SE}=0.05)$. During the last 


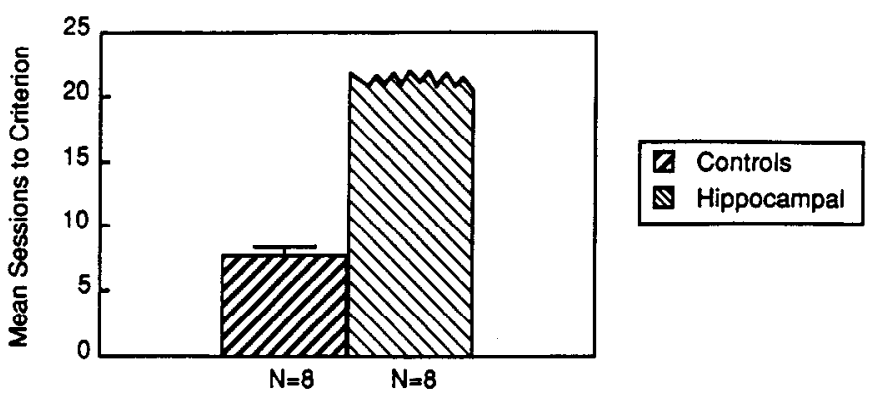

Figure 2. Mean sessions to criterion (with SEs) for the control and HF-lesioned birds on the sun compass-food location task. Note that none of the HF-lesioned birds learned the task within the 20 test sessions.

block of five sessions, mean $h$ was $0.36(\mathrm{SE}=0.05)$. These data indicate that during the course of training, there was a marginal but insignificant trend for the choices of the HF-lesioned birds to cluster more about the direction of food. It is unclear if this trend reflected any meaningful learning.

In contrast, mean $\mathbf{h}$ per session for the six control birds that were tested for at least eight sessions increased from 0.49 (SE $=0.07)$ during the first block of two sessions to $0.70(\mathrm{SE}=0.03)$ during the last block of two sessions. The increase over the four session blocks approached significance $[F(3,15)=2.77 ; P=$ 0.07].

\section{Behavior after clock-shift}

Learning on the part of the control lesioned birds suggests an ability to use the sun compass to associate a directional response with the location of food. However, to be certain that they were using the sun compass and not some other cue that we failed to control for, including compass information from the earth's magnetic field, the birds were clock-shifted $6 \mathrm{hr}$ slow and retested. Appropriately shifted directional choices in the experimental arena following clock-shift would demonstrate that the $\mathrm{CN}$-lesioned birds were indeed relying on the sun compass in solving the original task.

The data summarized in Figure 4 reveal that the mean directional choice of each bird during the 20 trial overtraining session was food oriented (mean direction $=354^{\circ}$, mean vector length $=0.98$ ). During the experimental session following clockshift, the pigeons' mean directional choices were shifted about $90^{\circ}$ clockwise (mean direction $=88^{\circ}$, mean vector length $=0.94$ ). This $90^{\circ}$ shift is exactly what would be expected following a slow clock-shift if the control birds were using the sun and compensating for its movement (i.e., the sun compass) to locate the food directionally. Given that the controls were using the sun compass to learn the original task, the data indicate that the HF-lesioned birds were unable to do similarly.

\section{Color discrimination}

The data presented suggest that HF-lesioned birds cannot use the sun compass to locate food directionally in an experimental arena. It is unlikely that the impairment is due to procedural aspects of the task. The HF-lesioned birds learned to take food from the food cups and explored the arena in a manner indistinguishable from the controls. Nonetheless, it could be argued that some unspecified procedural component of the task was the cause of the poor performance of the HF-lesioned birds. To address this issue, some of the $\mathrm{HF}$ and $\mathrm{CN}$ birds were trained in the same arena in a task where color rather than direction

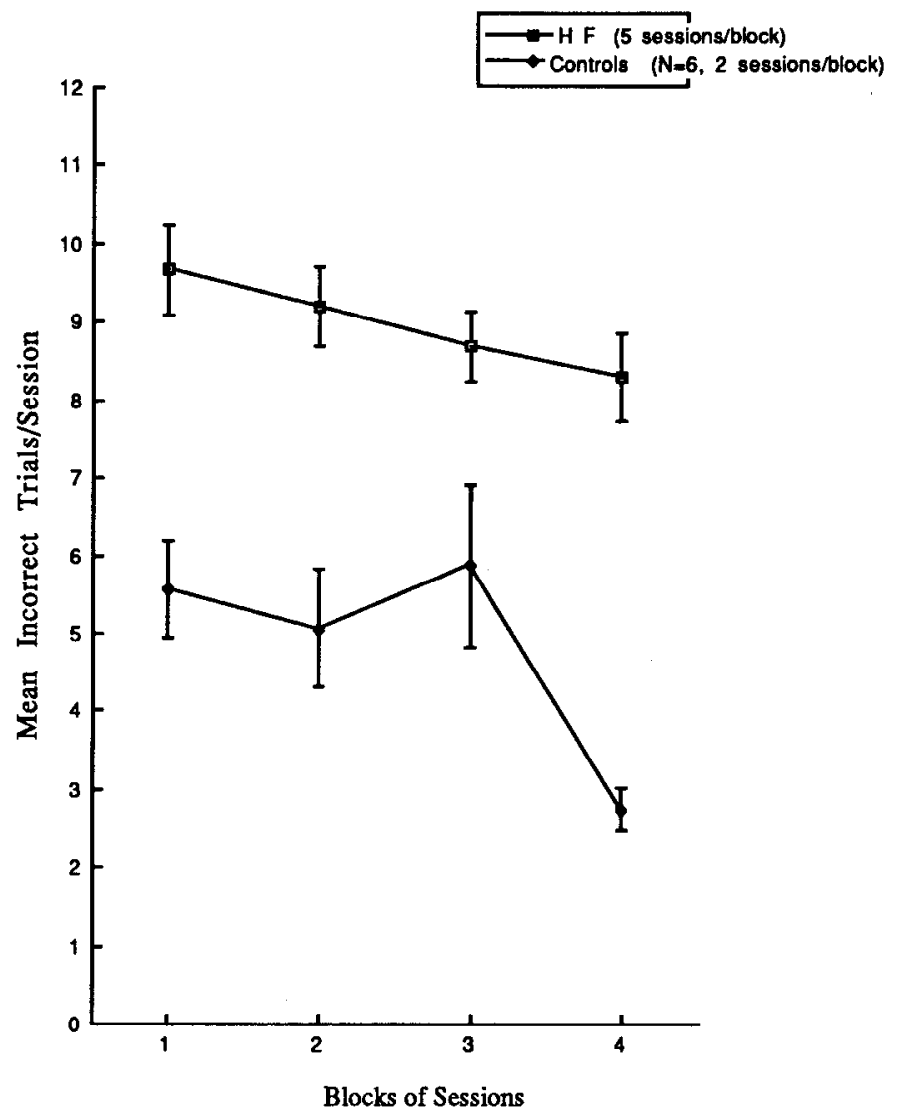

Figure 3. Mean number of incorrect trials (first choice errors) per session (with SEs) recorded from the HF-lesioned birds (open squares) and the $\mathrm{CN}$-lesioned control birds (solid diamonds) across four test blocks (HF: sessions 1-5, 6-10, 11-15, 16-20; CN: $N=6$, sessions $1-$ $2,3-4,5-6,7-8$ ) of the sun compass-food location task.

was the discrimitive stimulus used to locate food. Procedurally, this task was identical to the sun compass task.

The HF and control lesioned birds typically learned the task in a little more than four sessions (HF, mean sessions to criterion $=4.5, \mathrm{SE}=0.48 ; \mathrm{CN}$, mean sessions to criterion $=4.8, \mathrm{SE}$ $0.50)$. There was no between-group difference $[t(6)=0.361, P$ $>0.10]$. Comparing the two groups over the first four sessions (Fig. 5; all birds were tested for at least four sessions) revealed no between-group difference in errors $[F(1,6)=2.2, P>0.10]$, a significant overall reduction in errors across sessions $[F(3,18)$ $=22.9, P<0.001]$, and no interaction between group and errors across sessions $[F(3,18)=0.6, P>0.10]$. Although the sample size is not particularly large, the data clearly indicate that HFlesioned pigeons are at least as good as controls at learning this task. If anything, Figure 5 suggests that increasing the sample size might actually show the HF-lesioned birds to be somewhat better. If true, such a result would reflect either facilitation following $\mathrm{HF}$ lesion or impairment following $\mathrm{CN}$ lesion. Either possibility would be interesting, and awaits a more complete experimental analysis with untreated control birds. However, the critical point for the present study is that HF-lesioned birds are clearly unimpaired in this procedurally similar task where color is used as the discriminative stimulus.

\section{Discussion}

Hippocampal-ablated homing pigeons are impaired at using the sun compass to locate food directionally, but are unimpaired 


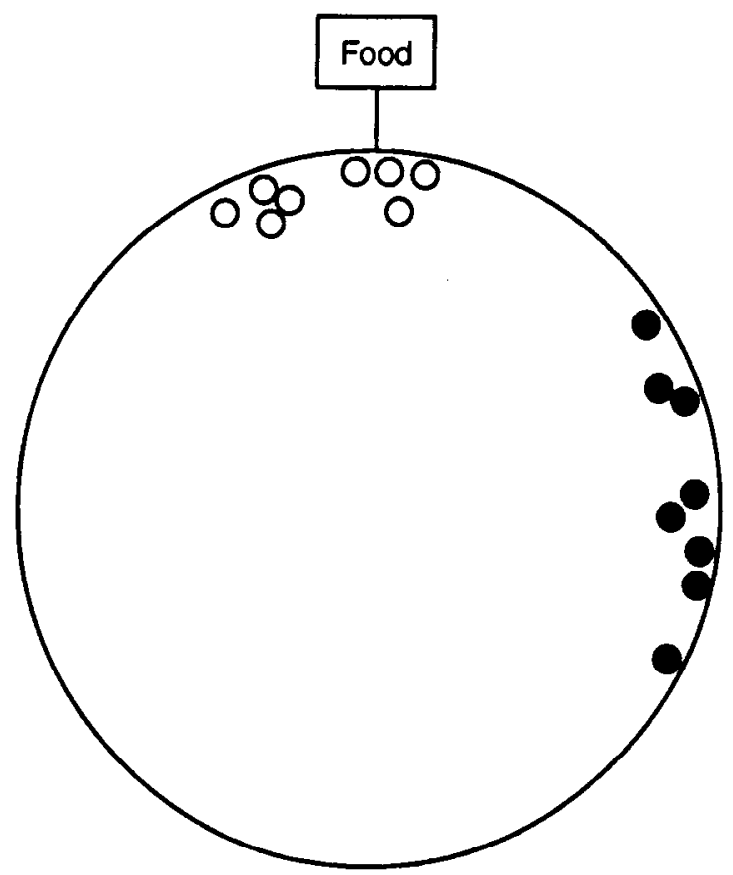

Figure 4. Mean directional choices of each control lesioned bird during the 20 trial overtraining session (open circles, based on the first food cup selection of each trial only) and the 20 trial clock-shift session (solid circles). The direction at the top of the diagram $\left(360^{\circ}\right)$ identifies the compass direction of the food during initial learning and the overtraining session.

when a color cue identifies food location. The magnitude of the deficit is extraordinary. The HF-lesioned birds used in this study had previously homed from $20 \mathrm{~km}$ away. Additionally, they explored the experimental arena and learned to take food from the cups like controls. Finally, the impairment in the sun compass task compared to the color task could not be a result of reduced visual acuity. HF lesions in homing pigeons have been shown to produce no deficit in visual acuity (Bingman and Hodos, 1992). Despite the absence of any sensory, motor, or obvious procedural impairment, the HF-lesioned birds offered no indication that they could ever use the sun compass to locate food directionally.

It may seem curious to conclude that HF-lesioned birds, which successfully homed from $20 \mathrm{~km}$ away, displayed a robust spatial learning impairment. However, successful homing does not imply good navigation. HF-lesioned birds return home, but do so more slowly and by taking less direct routes (Bingman and Mench, 1990; Bingman et al., 1990). The homing performance deficits observed in HF-lesioned birds presumably reflect impaired navigational learning. That they eventually return indicates that HF-lesioned pigeons can use alternative, less efficient strategies (e.g., random search) to return home.

Conservatively, the data indicate impaired sun compass use in the context of learning. As such, the results identify a role for $\mathrm{HF}$ in the operation of perhaps the most ubiquitous orientation cue used by animals in nature (Able, 1991). However, we believe the data have much broader significance for understanding the relationship between HF and spatial cognition. Using the sun compass to identify the directional location of food may be analogous to the process a pigeon would use to learn the directional location of a landmark with respect to the loft during landmark navigation learning (Wiltschko and

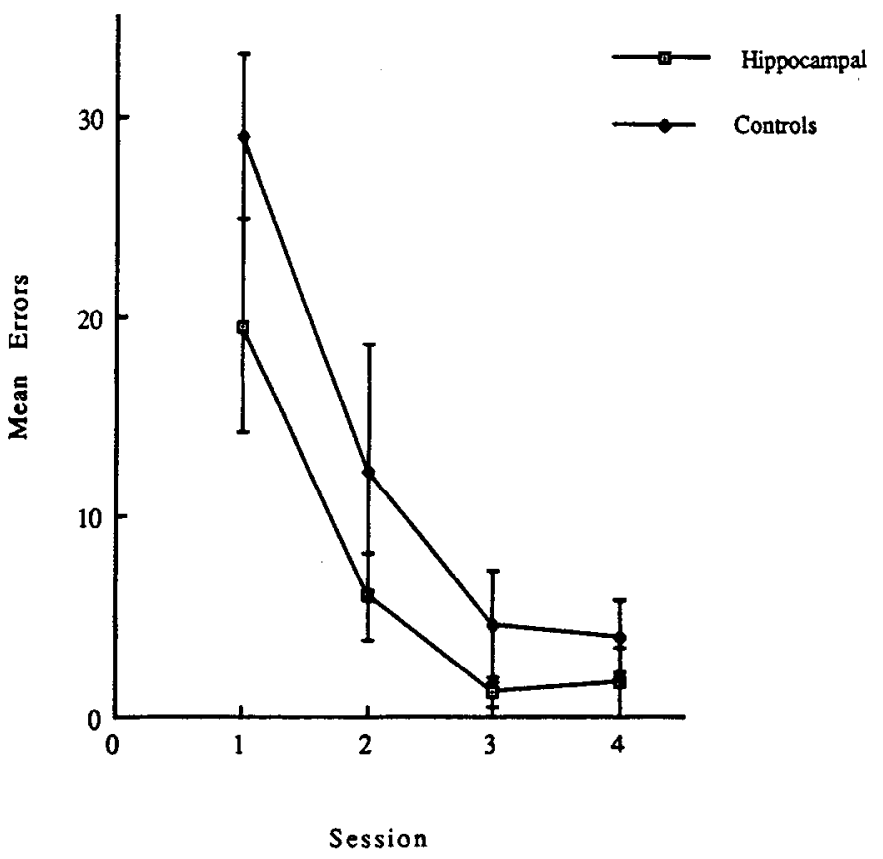

Figure 5. Mean number of errors (with SEs) committed by the HF(open squares) and $\mathrm{CN}$ - (solid diamonds) lesioned birds during the first four test sessions of the color-food location task.

Wiltschko, 1982, 1987), or learning the directional origin of some atmospheric quality (Ioalé et al., 1990) or stimulus gradient during navigational map learning (Wallraff, 1974). As such, the deficit displayed by HF-lesioned pigeons in learning to navigate by familiar landmarks (Bingman and Mench, 1990) and learning a navigational map (Bingman et al., 1990; Bingman and Yates, 1992) could be explained by their inability to use the sun compass as a directional reference to locate stimuli directionally in space.

It should be emphasized, however, that what the control birds learned in the test arena was a directional association mediated by the sun compass; for example, food is north. Therefore, the learning task examined the effect of HF lesion on a hypothesized process by which pigeons learn a map of space rather than any particular map. The directional rather than locational (map) nature of the learned association is highlighted by the observation that the controls' improved performance did not involve more correct choices to the food containing cup. Looking at the six control birds that were run for at least eight sessions, no improvement in correct responses to the food containing cup was found (looking at percentage correct responses to the food containing cup over four blocks of two sessions $[F(3,15)=0.74$, $P>0.10]$. They correctly chose the food containing cup on about $40 \%$ of the trials throughout the testing period. Their improvement, therefore, was a consequence of more correct choices to the two cups adjacent to the food. This result suggests that the control birds were not learning a location in the arena, but learning to orient in a particular direction that generally brought them closer to the food containing cup. The lack of improvement going to the food containing cup presumably reflects the directional nature of the task coupled with the variation in starting position discussed in the methods.

Even though the pigeons learned what might be considered a simple directional association, it is this process that is hypothesized to support map learning. Ioalé et al. (1990) elegantly 
showed that pigeons can use the type of directional association examined in the present study to acquire a partial map of space that can be used for navigation. For more complete map acquisition, a pigeon could presumably use a similar directional association mechanism to learn the directional relationship among a variety of stimuli in space. From the set of learned directional associations would emerge a map-like representation of the environment (Wiltschko and Wiltschko, 1982, 1987).

More generally, the data suggest the hypothesis that the role of $\mathrm{HF}$ in spatial cognition is to integrate information from a directional reference with features in the environment to construct map-like representations in the brain. In laboratory settings, HF-lesioned rodents (e.g., Morris et al., 1986) and birds (e.g., Sherry and Vaccarino, 1989) displaying impairments in spatial cognition would be interpreted to do so because they are unable to use a directional reference to polarize space and therefore are unable to code the directional relationship among relcvant stimuli. It is unclcar what might serve as a directional reference in a laboratory setting. Possibilities include asymmetries in the test room (Cheng, 1986) or even the earth's magnetic field (Wiltschko and Wiltschko, 1988).

Biegler and Morris (1993) recently reported that rodents are unable to acquire a map-like representation when landmarks are moved in a test arena. One interpretation of this result based on the hypothesis is that changing the position of the landmarks destabilizes the spatial relationship between them and some directional reference thus precluding map learning.

The hypothesis can also be used to explain the presence of both direction-sensitive cells (Taube et al., 1990) and place cells (O'Keefe and Conway, 1978) in the rat hippocampus. Conceptually, direction-sensitive cells would participate in the neural representation of an environmental, directional reference. During map learning, the emergent place fields of place cells (Wilson and McNaughton, 1993) would bc regulated by the directional reference system represented by activity in direction cells.

Evaluating the hypothesis in pigeons will require clarification of two critical, unresolved issues. An implicit assumption embedded in the hypothesis is that HF-lesioned homing pigeons have a sun compass that can be used for orientation, but not as a reference to learn the directional relationship among stimuli in space.

The distinction between having a sun compass for orientation that cannot be used as a directional reference for learning, and not having a sun compass at all may not appear immediately obvious, yet the distinction is of fundamental importance. Experienced homing pigeons possess at least two map-like mechanisms that allow them to determine their location in space relative to home, the navigational map and familiar landmarks. However, a map is insufficient to allow a bird to orient homeward. For example, a map can be used to determine onc is north of home and therefore fly south. But where is south? To identify directions in space (e.g., south) and guide orientation, experienced pigeons principally rely on their sun compass (SchmidtKoenig, 1979). The sun compass is a direction-finding mechanism used for orientation. It is not a map. To fly off in an approximate homeward direction from distant locations, pigeons rely on a two-step process. First they determine their location with respect to home using some map mechanism. They then use the sun compass to orient an appropriate homeward bearing (Wallraff, 1974).

Although basically an orientation cue for adult, experienced pigeons, the sun compass is additionally hypothesized to pro- vide a directional reference necessary for spatial learning. Young birds learning a navigational map, for example, would use the sun not only for orientation but as a directional reference for learning. Therefore, it is important to understand whether HFlesioned homing pigeons cannot directionally locate food in the test arena because they do not have a functional sun compass for orientation or because they cannot use the sun compass specifically for learning. If they are not able to orient by the sun compass, then HF must be considered critical for general sun compass orientation. However, if they have a sun compass for orientation, but cannot use it for learning, it would cmphasizc a role for $\mathrm{HF}$ in a cognitive process where the sun compass is used as a directional reference for spatial learning.

The available evidence suggests that HF-lesioned birds possess a sun compass for orientation. Homing pigeons that undergo HF lesions as adults are able to orient homeward from distant, unfamiliar locations (Bingman et al., 1988). Navigation and orientation mechanisms used from such sites are not disrupted by HF lesions. Given that homing pigeons preferentially use their sun compass for orientation (Füller et al., 1983), this result suggests that HF lesions do not disrupt sun compass orientation.

Young homing pigeons that underwent HF lesions were impaired in learning a navigational map as reflected in their inability to determine the direction home from distant, unfamiliar release sites. However, the same birds consistently oriented westward when released (Bingman et al., 1990). The latter result suggests that the young birds without an HF possessed a functional sun compass that allowed them to orient west. HF lesions in young birds would appear not to preclude learning a sun compass.

These two results suggest that the failure to use a sun compass to locate food directionally in the test arena was not a general consequence of not having a sun compass for orientation, but the specific inability to use it as a directional reference for learning. It is important to highlight that the two examples of possible sun compass use by HF-lesioned birds are both characterized by the sun compass not being used to learn about other stimuli (directional reference), but to simply orient a response (orientation cue) in the absence of learning something new.

The examples of likely sun compass use by HF-lesioned birds, however, are confounded by the possibility that the observed orientation was guided not by the sun but the earth's magnetic field (Wiltschko and Wiltschko, 1988). Clear demonstration that HF lesioned birds have a sun compass will require that such birds be clock-shifted and then released from a distant location. If the orientation of the pigeons is shifted in accordance with the clock-shift treatment, then sun compass use by HF-lesioned birds would be demonstrated.

The sccond issue that awaits clarification is the importance of time. The sun compass is based on spatial-temporal associations that take into account the movement of the sun during the course of the day. To use the sun compass to identify the location of a stimulus in space, therefore, an animal must rely on its internal sense of time. Therefore, it is important to consider whether HF is specifically involved in the neural regulation of the sun compass in the context of learning, as predicted by the hypothesis, or whether it plays a more general role in temporal associations. Meck (1988) and Meck and Church (1987) found that HF (fimbia-fornix) lesions and cholinergic manipulation, respectively, altered the timing of responses by rodents in an operant chamber. However, experiments examining the 
relationship between $\mathrm{HF}$ and temporal associations, and its possible role in explaining impaired sun compass-mediated learning, must look at time-regulated responses that vary in circadian time (e.g., Krebs and Biebach, 1989).

The results presented indicate that HF lesion has a devastating effect on the ability of homing pigeons to use the sun compass to locate food directionally in an outdoor, experimental arena. The performance deficit cannot be traced to motor, sensory, or procedural aspects of the task. As such, the data reveal HF involvement in the neural regulation of the avian sun compass in the context of learning. More importantly, the data suggest the hypothesis that the critical role HF plays in spatial cognition is enabling a directional reference to serve as a spatial framework for learning the directional relationship among stimuli in space. Potentially, the hypothesis is not limited to the sun compass but could apply to any spatial learning context known to involve HF.

\section{References}

Able KP (1991) Common themes and variations in animal oricntation systems. Am Zool 31:157-167.

Batschelet E (1981) Circular statistics in biology. New York: Academic.

Berthold P (1991) Orientation in birds. Basel: Birkhäuser.

Biegler R, Morris RGM (1993) Landmark stability is a prerequisite for spatial but not discrimination learning. Nature 351:631-633.

Bingman VP (1992) The importance of comparative studies and ecological validity for understanding hippocampal structure and cognitive function. Hippocampus 2:213-219.

Bingman VP, Hodos W (1992) Visual performance of homing pigeons following hippocampal lesion. Behav Brain Res 51:203-209.

Bingman VP, Mench JA (1990) Homing behavior of hippocampus and parahippocampus lesioned pigeons following short-distance relcases. Behav Brain Res 40:227-238.

Bingman VP, Yates G (1992) Hippocampal lesions impair navigational learning in experienced homing pigeons. Behav Neurosci 106: 229-232.

Bingman VP, Ioalé P, Casini G, Bagnoli P (1988) Hippocampal ablated homing pigeons show a persistent impairment in the time taken to return home. J Comp Physiol [A] 163:559-563.

Bingman VP, Bagnoli P, Ioale P, Casini G (1989) Behavioral and anatomical studies of the avian hippocampus. In: Neurology and neurobiology, Vol. 52, The hippocampus-new vistas (Chan-Palay V, Koehler C, eds), pp 379-394. New York: Liss.

Bingman VP, Ioalé P, Casini G, Bagnoli P (1990) The avian hippocampus: evidence for a role in the development of the homing pigeon navigational map. Behav Neurosci 104:906-911.

Brauth SE, McHale CM, Brasher CA, Dooling RJ (1987) Auditory pathways in the budgerigar. I. Thalamo-telencephalic projections. Brain Behav Evol 30:174-199.

Cheng K (1986) A purely geometric module in the rat's spatial representation. Cognition 23:149-178.

Davidson TL, McKernan MG, Jarrard LE (1993) Hippocampal lesions do not impair negative patterning: a challenge to configural association theory. Behav Neurosci 107:227-234.

Füller E, Kowalski U, Wiltschko R (1983) Orientation of homing pigeons: compass orientation vs. piloting by landmarks. J Comp Physiol [A] 153:55-58.

Graue L (1963) The effects of phase shifts in the day-night cycle on pigeon homing at distances of less than one mile. Ohio J Sci 63:214217.

Ioalé P, Nozzolini M, Papi F (1990) Homing pigeons do extract directional information from olfactory stimuli. Behav Ecol Sociobiol 26:301-305.

Jacobs LF, Gaulin SJC, Sherry DF, Hoffman GE (1990) Evolution of spatial cognition: sex-specific patterns of spatial behavior predict hippocampal size. Proc Natl Acad Sci USA 87:6349-6352.

Jarrard LE (1993) On the role of the hippocampus in learning and memory in the rat. Behav Neural Biol 60:9-26.

Karten H, Hodos W (1967) A stereotaxic atlas of the brain of the pigeon Columba livia. Baltimore: John Hopkins UP.
Klüver H, Barrera E (1953) A method for combined staining of cells and fibers in the nervous system. Neuropathol Exp Neurol 12:400403.

Kramer G (1959) Recent experiments on bird orientation. Ibis 101: $399-416$.

Kramer G, Riese E (1952) Die Dressur von Brieftauben auf Kompassrichtung in Wahlkaefig. Z Tierpsychol 9:245-251.

Krebs JR, Biebach H (1989) Time-place learning by garden warblers (Sylvia borin): route or map? Ethology 83:248-256.

Krebs JR, Sherry DF, Healy SD, Perry VH, Vaccarino AL (1989) Hippocampal specialization of food-storing birds. Proc Natl Acad Sci USA 86:1388-1392.

Krushinskaya N (1966) Some complex forms of feeding behaviour of nutcracker Nucifraga caryocatactes, after removal of old cortex. $\mathrm{Zh}$ Evol Biokhim Fisiol II:563-568.

Lipp HP, Schwegler H, Heimrich B, Cerbone A, Sadile AG (1987) Strain-specific correlations between hippocampal structural traits and habituation in spatial novelty situation. Behav Brain Res 24:111123.

Meck WH (1988) Hippocampal function is required for feedback control of an internal clock's criterion. Behav Neurosci 102:54-60.

Meck WH, Church RM (1987) Cholinergic modulation of the content of spatial memory. Behav Neurosci 101:457-464.

Morris RGM, Garrud P, Rawlins J, O'Keefe J (1982) Place navigation impaired in rats with hippocampal lesions. Nature 297:681-683.

Nadel L (1991) The hippocampus and space revisited. Hippocampus $1: 221-229$

O'Keefe J, Conway DH (1978) Hippocampal place units in the freely moving rat: why they fire where they fire. Exp Brain Res 31:573-590.

O'Keefe J, Nadel L (1978) The hippocampus as a cognitive map. Oxford: Clarendon.

Olton DS, Becker J, Handelmann G (1979) Hippocampus, space and memory. Behav Brain Sci 2:313-365.

Schmidt-Koenig K (1958) Experimentelle Einflussnahme auf die 24Stunden-Periodik bei Brieftauben und deren Auswirkungen unter besonderer Berücksichtigung des Heimfindevermogens. Z Tierpsychol 15:301-331.

Schmidt-Koenig K (1961) Die Sonne als Kompass in Heimorientierungssystem der Breiftauben. Z Tierpsychol 18:221-244.

Schmidt-Koenig K (1979) Avian orientation and navigation. New York: Academic.

Sherry DF, Vaccarino AL (1989) The hippocampus and memory for food caches in blackcapped chickadees. Behav Neurosci 103:308318.

Sherry DF, Vaccarino AL, Buckenham K, Herz RS (1989) The hippocampal complex of food-storing birds. Brain Behav Evol 34:308317.

Sutherland RJ, Rudy JW (1989) Configural association theory: the role of the hippocampal formation in learning, memory and amnesia. Psychobiology 17:129-144.

Taube JS, Muller RU, Ranck Jr JB (1990) Head-direction cells recorded from the postsubiculum in freely moving rats. I. Description and quantitative analysis. J Neurosci 10:420-435.

Wallraff HG (1974) Das Navigationsystem der Voegel. Munich: Oldenburg.

Wallraff HG (1990) Navigation by homing pigeons. Ethol Ecol Evol 2:81-115.

Wallraff HG, Kiepenheuer J, Streng A (1993) Further experiments on olfactory navigation and non-olfactory pilotage by homing pigeons. Behav Ecol Sociobiol 32:387-390.

Wilson MA, McNaughton BL (1993) Dynamics of the hippocampal ensemble code for space. Science 261:1055-1058.

Wiltschko W, Balda RP (1989) Sun compass orientation in seedcaching scrub jays (Aphelocoma coerulescents). J Comp Physiol [A] 164:717-721.

Wiltschko W, Wiltschko R (1982) The role of outward-journey information in the orientation of homing pigeons. In: Avian navigation (Papi F, Wallraff HG, eds), pp 239-252. Heidelberg: Springer.

Wiltschko W, Wiltschko R (1987) Cognitive maps and navigation in homing pigeons. In: Cognitive processes and spatial orientation in animal and man, I (Ellen P, Thinus-Blanc C, eds), pp 201-216. Netherlands: Nijhoff.

Wiltschko W, Wiltschko R (1988) Magnetic orientation in birds. In: Current ornithology, Vol V (RF Johnston, ed), pp 67-121. New York: Plenum. 